\title{
Bireysel Emeklilik Şirketi Seçimine Analitik Hiyerarşi Prosesi ve Gri İlişkisel Analiz Yöntemlerinin Uygulanması

\author{
(The Application of Analytic Hierarchy Process and Gray Relational Analysis Methods in \\ the Selection of Private Pension Company)
}

\author{
Elçin NOYAN ID ت̇doğan GAVCAR ${ }^{\mathrm{b}}$ (iD su TOSUN GAVCAR ${ }^{\mathrm{c}}$ \\ a Muğla Sıtkı Koçman Üniversitesi, Sosyal Bilimler Enstitüsü, Muğla. elcinnoyan@hotmail.com \\ b Muğla Sıtkı Koçman Üniversitesi, İktisadi ve İdari Bilimler Fakültesi, Muğla. gavcar@mu.edu.tr \\ c Pamukkale Üniversitesi, Sosyal Bilimler Enstitüsü, Denizli. c_tosun@hotmail.com
}

\begin{tabular}{|c|c|}
\hline MAKALE BİLGİSİ & ÖZET \\
\hline $\begin{array}{l}\text { Anahtar Kelimeler: } \\
\text { Bireysel Emeklilik Sistemi } \\
\text { Çok Kriterli Karar Verme } \\
\text { AHS } \\
\text { GRA } \\
\text { Emeklilik Yatırım Fonları }\end{array}$ & $\begin{array}{l}\text { Amaç - Bu çalışmanın temel amacı bireylerin bireysel emeklilik yatırımları kararlarının } \\
\text { Türkiye'de faaliyette bulunan bireysel emeklilik şirketleri arasından en uygun olan şirkete } \\
\text { yönlendirilmesi konusunda fikir verebilmektir. } \\
\text { Yöntem - Araştırma problemi belirli kriterler doğrultusunda bireysel emeklilik şirketlerinin } \\
\text { sıralanmasıdır. Veri setini beş adet Bireysel Emeklilik Şirketleri'ne ait Şubat } 2019 \text { dönemine ait } \\
\text { güncel veriler oluşturmaktadır. Kriter ağırlıklandırmaları altı adet yatırım yapmayı planlayan } \\
\text { birey ve beş adet bireysel emeklilik danışmanı ile yüz yüze görüşme ile hesaplanmıştır. AHS } \\
\text { Yöntemi'nden elde edilen ağırlıklar GİA Yöntemi'ne uygulanmıstır. } \\
\text { Bulgular - Araştırma sonuçlarına göre AHS yöntemine göre en önemli kriterin 'katılımcı sayısı' } \\
\text { olduğu dolayısıla katılımçların birbirlerini etkiledikleri, yatırım yapmayı planlan bireylerin } \\
\text { birbirlerinin tavsiyelerine önem verdikleri, daha önce yatırım yapmış bireylerin yatırım } \\
\text { yaptıkları şirketlerin hizmetlerinden memnun kaldıkları sonuçlarına ulaşılmıştır. } \\
\text { Tartışma -Türkiye'de bireysel emeklilik şirketlerine yatırım için toplanan kaynak, devlet } \\
\text { katkısına rağmen OECD ülkelerine kıyasla sınırlı kalmaktadır. Bu oranın Türkiye'de sınırlı } \\
\text { olmasının başlıca sebepleri arasında enflasyon oranının yüksek olması ve ortalama gelirin ise } \\
\text { düşük olması sayılabilir. Çalışmadan elde edilen bulgular Genç ve ark. (2015), Dinçer ve } \\
\text { Görener (2011) ve Ertuğrul \& Öztaş (2016)'ın yapmış oldukları çalışmalar ile benzerlik } \\
\text { göstermektedir. Karar vericiler değiştikçe kriter ağırlıları da değişeceğinden uygulama } \\
\text { sonuçları farklılaşacaktır. }\end{array}$ \\
\hline ARTICLE INFO & ABSTRACT \\
\hline $\begin{array}{l}\text { Keywords: } \\
\text { Private Pension System } \\
\text { Multi Criteria Decision Making } \\
\text { (MCDM) } \\
\text { AHP } \\
\text { GRA } \\
\text { Pension Mutual Funds }\end{array}$ & $\begin{array}{l}\text { Purpose - The main objective of this study is to give an idea of pension investment decisions of } \\
\text { individuals operating in Turkey guiding the company through the most appropriate pension } \\
\text { companies. } \\
\text { Design/methodology/approach - The research problem is the sequencing of private pension } \\
\text { companies in line with certain criteria. The data set is the current data for the period of February } \\
2019 \text { belonging to five Private Pension Companies. Criterion weightings were calculated by } \\
\text { face-to-face interviews with the individual and five individual pension counselors who planned } \\
\text { to invest. The weights from the AHP Method were applied to the GRA method. }\end{array}$ \\
\hline $\begin{array}{l}\text { Received } 1 \text { March } 2019 \\
\text { Revised } 19 \text { April } 2019 \\
\text { Accepted } 4 \text { May } 2019\end{array}$ & $\begin{array}{l}\text { Findings - According to the results of the survey, the most important criterion was 'number of } \\
\text { participants' according to AHP Method. } \\
\text { Discussion - the collected resources to invest in private pension company in Turkey, despite the } \\
\text { state contribution is limited compared to OECD countries. This rate is higher among the main } \\
\text { causes of the inflation rate in Turkey is limited and the average income is considered to be low. } \\
\text { Findings from the study Genç et al. (2015), Dinçer, Görener (2011) and Ertuğrul, Öztaş (2016) } \\
\text { show similarities with their studies. As the decision makers change, the criteria weights will } \\
\text { change and the implementation results will be different. }\end{array}$ \\
\hline
\end{tabular}




\section{Giriş}

Bireysel emeklilik sistemi, bireylerin çalışmaları süresince yapmış oldukları tasarrufları uzun vadeli yatırıma dönüştürüp emekli olduklarında gelir elde etmek için başvurdukları özel emeklilik sistemidir. Amaçları ise bireylerin emekliliğe yönelik tasarruflarının yatırıma yönlendirilmesi ile ek gelir sağlamak, ekonomiye uzun vadede kaynak sağlamak, istihdamı artırmak, toplanan tasarruflar ile emeklilik yatırım fonlarına aktarılması, tasarrufların yastık altından çıkarılıp piyasada uzman kişiler tarafından değerlendirilmesi ile ekonomik kalkınmaya yardımcı olmaktır. Gönüllülük esasına dayalı özel bir emeklilik sistemidir (egm.gov.tr). Bireysel Emeklilik Sistemi, Türkiye'de ilk fiili olarak 27 Ekim 2003 yılında hayata geçirilmiştir. Bireyleri tasarrufa yönlendirerek emeklilik dönemlerinde ek gelir olarak kullanabilmelerini sağlama amaçlı sistem, ülke ekonomisi için de olumlu etki yaratmaktır (Boulier ve ark. 2001:173). Türkiye'de bireysel emeklilik sektörünün her geçen gün büyümekte, önemi artmaktadır Bireysel Emeklilik Sistemi (BES) seçiminde, alternatiflerin çokluğu ve şirketlerin sahip olduğu kriterlerin fazlalığı BES şirketleri arasında bir seçim yapılırken birçok kriterin değerlendirilmesi gerekmektedir (Karakaya ve ark. 2014: 3).

Emeklilik Gözetim Merkezi (EGM)'nin 8 Şubat 2019 tarihi itibariyle yayınlamış olduğu bireysel emeklilik sistemi verileri incelendiğinde:

Tablo I: Bireysel Emeklilik Sistemi Verileri

\begin{tabular}{|cc|}
\hline \multicolumn{2}{|c|}{ Bireysel Emeklilik Sistemi Verileri } \\
Toplam Katılımcı Sayısı & 6.835 .549 kişi \\
Devlet Katkısı Fon & $12.456,3$ milyon TL \\
Katkı Payı Tutarı & $58.812,6$ milyon TL \\
Yatırıma Yönlenen Tutar & $57.886,9$ milyon TL \\
Toplam Fon Büyüklüğü & 92,1 milyar TL \\
Katılımcıların Fon Tutarı & 79.654 .3 milyon TL \\
\hline (https://www.egm.org.tr)
\end{tabular}

Tablo 1' de Bireysel Emeklilik Sistemi verilerinden, toplam katılımcı sayısı, devlet katkısı fon tutarı, katkı payı tutarı, yatırıma yönlenen tutar ve katılımcıların fon tutarları yer almaktadır.

Tablo 2: Fonların ve Mevduatın Brüt Getirisi

\begin{tabular}{|c|c|c|}
\hline & $\begin{array}{c}\text { Fonların Ağırlıklı } \\
\text { Ortalama }\end{array}$ & $\begin{array}{c}\text { Mevduat Brüt } \\
(\%)\end{array}$ \\
\hline $\begin{array}{c}\text { Başlangıçtan } \\
\text { İtibaren }\end{array}$ & 445 & 531 \\
\hline Son 10 yıl & 203 & 157 \\
\hline Son 5 yıl & 82 & 72 \\
\hline 2018 yılı & 14 & 18 \\
\hline
\end{tabular}

(http://www.tkyd.org.tr)

Tablo 2'de gönüllü BES fonları, başlangıçtan itibaren ortalama \% 445 oranında birikimli ağırlıklı net getiriye sahiptir. 10 yılda ortalama \% 203, son 5 yılda \% 82'lik bir getiriye sahiptir. 2018 yılında bu getiri $\% 14$ dolaylarındadır. 
E. Noyan - E. Gavcar - C. Tosun Gavcar 11/2 (2019) 835-847

Tablo 3. Katılımcıların Yaş Dağılımı

\begin{tabular}{|cc|}
\hline Yaş & \% \\
25 yaş altı & 5,05 \\
25-34 yaş & 25,85 \\
$35-44$ yaş & 33,65 \\
$45-55$ yaş & 24,95 \\
56 yaş ve üzeri & 10,51 \\
\hline
\end{tabular}

(https://www.egm.org.tr)

Tablo 3'te katılımcıların yaş dağılımları incelendiğinde, \% 5,05'ini 25 yaş altı,\%25,85'ini 25-34 yaş arası, en yüksek olduğu yaş aralığı 35-44, \%24,95'ini 45-55 yaş aralığ1 ve \%10,51 'ini 56 yaş üzeri bireyler oluşturmaktadır.

\section{Tablo 4. En Fazla Katılımcının Yerleşik Olduğu İlk On İl}

\begin{tabular}{|cc|}
\hline Şehir & \% \\
İstanbul & 27,92 \\
Ankara & 9,15 \\
İzmir & 6,95 \\
Antalya & 4,17 \\
Bursa & 4 \\
Kocaeli & 2,62 \\
Adana & 2,53 \\
İçel & 2,12 \\
Muğla & 1,99 \\
Konya & 1,97 \\
\hline
\end{tabular}

(https://www.egm.org.tr)

Tablo 4'te katılımcıların yaşadıkları şehir dağılımı incelendiğinde ise ilk üç sırayı İstanbul, Ankara ve İzmir'in aldığı görülmektedir. 
E. Noyan - E. Gavcar - C. Tosun Gavcar 11/2 (2019) 835-847

Tablo 5: OECD Ülkelerinde Fon ve Bireysel Emeklilik Düzenlemelerinin Getirisinin Reel Yıllık Net Yatırım Oranları (\%)

\begin{tabular}{|c|c|c|c|}
\hline & 2015 & 2016 & 2017 \\
\hline \multicolumn{4}{|c|}{ OECD Ülkeleri } \\
\hline Avustralya & 7,8 & 3,3 & 7,3 \\
\hline Avusturya & 1,2 & 2,6 & 3,7 \\
\hline Belçika & 2,6 & 3,5 & 3,1 \\
\hline Kanada & 5,1 & 4,0 & 5,7 \\
\hline Şili & 1,5 & 1,5 & 5,6 \\
\hline Çek Cumhuriyeti & 1,0 & $-1,2$ & $-1,8$ \\
\hline Danimarka & 1,8 & 5,9 & 3,9 \\
\hline Estonya & 2,9 & 1,0 & $-0,1$ \\
\hline Finlandiya & 5,3 & 4,0 & 6,7 \\
\hline Fransa &.. &.. & 3,1 \\
\hline Almanya & 3,1 & 2,1 & 2,1 \\
\hline Yunanistan & 4,7 & 4,2 & 6,9 \\
\hline Macaristan & 3,7 & 4,8 & 4,7 \\
\hline İzlanda & 7,5 & $-0,3$ & 5,3 \\
\hline İrlanda & 4,5 & 8,1 & 6,3 \\
\hline İsrail & 4,3 & 3,8 & 7,1 \\
\hline İtalya & 1,7 & 2,0 & 2,0 \\
\hline Japonya &.. &.. & 3,2 \\
\hline Kore & 2,5 & 2,0 & 1,9 \\
\hline Letonya & 1,4 & 0,0 & 0,8 \\
\hline Litvanya & 4,6 & 2,6 & 0,3 \\
\hline Luxemburg & 0,6 & 3,0 & 1,2 \\
\hline Meksika & $-0,8$ & $-0,4$ & 1,5 \\
\hline Hollanda & 0,9 & 8,6 & 4,5 \\
\hline Norveç & 1,9 & 2,0 & 6,1 \\
\hline Polonya & $-6,1$ & 8,3 & 14,5 \\
\hline Portekiz & 2,1 & 0,6 & 3,2 \\
\hline Slovak Cumhuriyeti & 0,8 & 2,5 & 0,4 \\
\hline Slovenya & 6,2 & 6,9 & 2,2 \\
\hline İspanya & 2,1 & 1,0 & 2,2 \\
\hline İsveç & 2,7 & 4,6 &.. \\
\hline İsviçre & 2,1 & 3,9 & 6,4 \\
\hline Türkiye & $-6,1$ & 2,1 & 2,9 \\
\hline Birleşik Krallık & 4,4 & 12,7 &.. \\
\hline A.B.D. & $-2,2$ & 2,6 & 7,5 \\
\hline
\end{tabular}

(OECD Global Pension Statistics)

Tablo 5'te OECD ülkelerinin fon ve bireysel emeklilik düzenlemelerinin getirisinin reel yıllık net yatırım oranları (\%) incelendiğinde en yüksek oran Polonya'da (\%14,5) daha sonra ise A.B.D. $(\% 7,5)$ ve İsrail ‘de (\% $7,1)$ olduğu görülmektedir. Türkiye ise sıralamanın gerisinde yer almaktadır.

Yapılan çalışmalar incelendiğinde; Altay (2013), Türkiye'de Bireysel Emeklilik Sistemi: Aydın örneğine, Apak ve Taşçyan (2010), Türkiye'de Bireysel Emeklilik Sistemi'nin gelişimine, Ayaydın (2013), Türkiye'deki emeklilik yatırım fonlarının performanslarının analizine, Can (2010), Bireysel emekliliğin Türkiye'deki durumu ve gelişimine, Dağlı ve ark. (2008), Türkiye'deki Bireysel Emeklilik yatırım fonlarının performans değerlendirmesine, Ertuğrul ve Öztaş (2016), COPRAS (Complex Proportional Assessment) ve TOPSIS (Technique for Order Preference by Similarity to Ideal Solution) yöntemleri ile Bireysel Emeklilik 
planı seçimine, Ege ve ark. (2011), Türkiye'deki emeklilik yatırım fonlarının yatırım performanslarının analizine, Karakaya (2014), Türkiye'deki emeklilik şirketlerinin performanslarının veri zarflama analizi ile ölçülmesine, Genç ve ark. (2015), MACBETH (Measuring Attractiveness by a Categorical Based Evaluation Technique) yaklaşımı ile bireysel emeklilik sistemi seçimine, Korkmaz ve Uygurtürk (2008), Türkiye'deki emeklilik fonları ile yatırım fonlarının performans karşılaştırması ve fon yöneticilerinin zamanlama yeteneklerine, Kula ve ark. (2016), Borsa İstanbul'da işlem gören sigorta ve BES şirketlerinin finansal performanslarının Gri ilişkisel analiz yöntemi ile incelenmesine, Peker ve Baki (2011), Gri İlişkisel Analiz Yöntemi ile incelenmesine, Türk sigortacılık sektörünün performans ölçümüne, Sezgin ve Yıldırım (2015), Türkiye'de bireysel emeklilik sisteminin etkinliğine, Göktolga ve Karakış (2018), Bireysel emeklilik şirketlerinin finansal performanslarının Bulanık AHS ve VIKOR Yöntemi ile analizine, Şener ve Akın (2010), bireylerin bireysel emeklilik sistemlerine bakış açları ile BES'e giriş kararlarını etkileyen faktörlere, Wu ve ark. (2009), Bulanık ÇKKV yöntemleri ile bankaların performanslarının analizine, Sönmez (2012), BES' e girişte önem verilen kriterlerin tercih sıralamasının AHS ile belirlenmesine, İşcan, Aydın (2018), zaman tercihi, hazzın ertelenmesi ve bireysel emeklilik kararlarına yönelik çalışmalar yapmışlardır.

\section{Metodoloji}

\subsection{Araştırmanın Amacı}

Çalışmada amaç 17 adet bireysel emeklilik şirketinden beş adedini, katılımcı sayısı, katılımcıların fon tutarı, devlet katkısı fon tutarı, katkı payı tutarı, emekli olan katılımcı sayısı, sözleşme ve sertifika sayıları, fon büyüklüğü, yatırıma yönlenen tutar, kriterlerini temel alarak sıralamak, söz konusu kriterlerden tercih aşamasında hangilerinin daha fazla etkili olduğunu saptamak, böylelikle yatırım yapmayı planlayan bireylere, bireysel emeklilik şirketlerine ve literatüre katkı sağlamak amaçlanmıştır.

\subsection{Yöntem}

Çalışmada bireysel emeklilik şirketleri, Çok Kriterli Karar Verme (ÇKKV) Yöntemleri'nden olan Analitik Hiyerarşi Süreci (AHS) ve Gri İlişkisel Analiz (GİA) yöntemleri kullanılarak sıralanmıştır. Çalışmada ilk olarak AHP yöntemi ile kriter ağırlıkları hesaplanmış daha sonra GİA yöntemi ile hesaplamalar yapılarak sıralamalar gerçekleştirilmiştir. Ağırlıklandırma durumuna göre de ayrıca her iki yöntemde sıralamalar yapılmış, sonuçlar birbirleri ile kıyaslanmıştır.

\subsubsection{Analitik Hiyerarşi Süreci}

Analitik Hiyerarşi Süreci, 1980 yılında Saaty tarafından karmaşık problemlerin çözüm sürecini kolaylaştırmak amacıyla literatüre kazandırılmıştır. AHS yöntemi ile problem hiyerarşik olarak modellenerek hem kriterler hem de alternatifler arası ikili karşılaştırma temeline dayanır. Bu ikili karşılaştırmalar kriterlerin veya alternatiflerin birbirlerine göre önem derecelerinin karşılaştırılmasıdır (Çelikbilek, 2018: 43).

AHS yöntemi ile problemlerin çözümü altı aşamadan oluşmaktadır (Aydın vd., 2009: 72-76):

Adım 1. Problemin net bir şekilde tanımlanır, hiyerarşik model oluşturulur. Hiyerarşik modelde; amaç, kriterler ve alternatifler yer almaktadır.

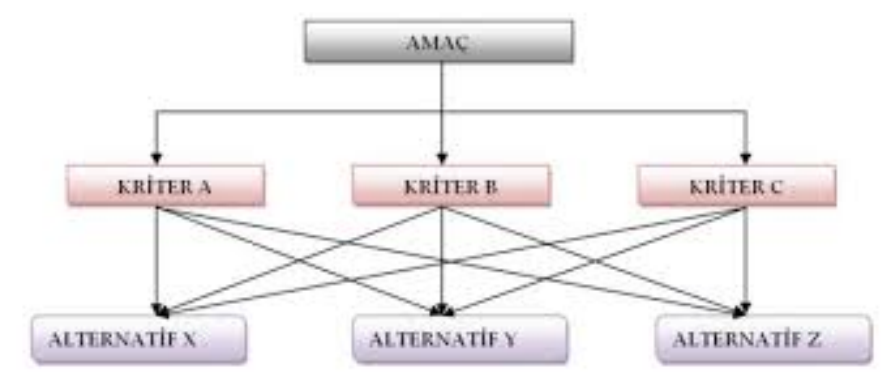

Şekil I. Basit Hiyerarşi Modeli (Tzeng \& Huang, 2011: 8)

Adım 2. Kriterler arası karşılaştırma matrisinin oluşturulur, karşılaştırma matrisi Tablo 7' de görülmektedir. 
E. Noyan - E. Gavcar - C. Tosun Gavcar 11/2 (2019) 835-847

Tablo 7: İkili Karşılaştırma Matrisinin Elde Edilmesi

\begin{tabular}{|llll|}
\hline & Kriter 1 & Kriter 2 & Kriter $n$ \\
Kriter 1 & w1/w1 & w1/w2 & w1/wn \\
Kriter 2 & w2/w1 & w2/w2 & w2/wn \\
Kriter $\mathrm{n}$ & wn/w1 & wn/w2 & wn/wn \\
\hline
\end{tabular}

(Tzeng \& Huang, 2011: 8)

Kriterler arasında ikili karşılaştırma matrisleri oluşturulurken Saaty'nin 1-9 ölçeğinden yararlanılmıştır.

Tablo 8: Karşılaştırma Ölçeği

\begin{tabular}{|cc|}
\hline Önem Değerleri & Değer Tanımları \\
1 & Biraz daha önemli \\
3 & Oldukça önemli \\
5 & Çok önemli \\
7 & Son derece önemli \\
9 & Ara değerler \\
$2,4,6$ ve 8 & \\
\hline
\end{tabular}

(Vaidya, Kumar, 2006: 1-29)

Elde edilen ikili karşılaştırma değerleri, kriterlerin kesişim hücresine faktörler karşılaştırılırken birbirlerine göre önem değerleri temel alınır. Tablo 8'deki önem değerleri kullanılarak karşılaştırma yapılır. Köşegenin altıda kalan bileşenler için 1 . Formülden yararlanılır.

$$
a_{j i}=\frac{1}{a_{i j}}
$$

Adım 3. İkili karşılaştırma matrislerinin satır ve sütun toplamlarının alınarak normalize edilmesi, kriterlerin birbirlerine göre önem seviyelerini ifade eder. Karşılaştırma matrisini oluşturan sütun vektörler kullanılarak ve $n$ adet ve $n$ bileşenli $B$ sütun vektörü hesaplanırken 2 . formülden yararlanılır.

$$
b_{i j}=\frac{a_{i j}}{\sum_{i=1}^{n} a_{i j}}
$$

İşlemler tekrar edildiğinde faktör sayısı kadar B sütun vektörü elde edilecektir. $n$ adet B sütun vektörü ile C matrisi elde edilir.

$$
C=\left[\begin{array}{cccc}
c_{11} & c_{12} & \ldots & c_{1 n} \\
c_{21} & c_{22} & \ldots & c_{2 n} \\
\cdot & & & \cdot \\
\cdot & & & \cdot \\
\cdot & & & \cdot \\
c_{n 1} & c_{n 2} & \ldots & c_{n n}
\end{array}\right]
$$

C matrisinden yararlanarak, faktörlerin birbirlerine göre önem değerine göre dağılımlarına bakılır. 4. formül ile C matrisini oluşturan satırların aritmetik ortalaması alınır ve öncelik vektörüne (w) ulaşılır. 
E. Noyan - E. Gavcar - C. Tosun Gavcar 11/2 (2019) 835-847

$$
w_{i}=\frac{\sum_{j=1}^{n} c_{i j}}{n}
$$

Adım 4. Tutarılıı Oranı (CR) hesaplanırken faktör sayısı ve temel değer $(\lambda)$ katsayısı karşılaştırması temel alınir.

$$
E_{i}=\frac{d_{i}}{w_{i}} \quad(\mathrm{i}=1,2, \ldots, \mathrm{n})
$$

$\lambda$ değerinin hesaplanması için $\mathrm{A}$ karşılaştırma matrisi ile $\mathrm{W}$ öncelik vektörünün matris çarpımından $\mathrm{D}$ sütun vektörü elde edilir.

$$
\lambda=\frac{\sum_{i=1}^{n} E_{i}}{n}
$$

$\lambda$ hesaplandıktan sonra Tutarlılık Göstergesi (CI), 8. formül ile hesaplanır (Saaty, 2013:121).

$$
C I=\frac{\lambda-n}{n-1}
$$

Formülde, $n$ : Karar alternatifi sayısını ve RI: Rastlantısal indeks değerini ifade etmektedir. RI değerleri Tablo 9'da görülmektedir.

Tablo 9: Rastlantısal İndeks Değerleri

\begin{tabular}{|ccccccc|}
\hline $\mathrm{n}$ & 3 & 4 & 5 & 6 & 7 & 8 \\
$\mathrm{RI}$ & 0,58 & 0,9 & 1,12 & 1,24 & 1,32 & 1,41 \\
\hline
\end{tabular}

(Kaynak: Tzeng, Huang, 2011: 8)

Adım 5. Tutarlılık analizlerinin yapılması

Uyum İndeksi (CI), Rasgele İndeks (RI) değerlerinin sonucu ile tutarlılık oranı hesaplanır. Güvenilir ve gerçekçi sonuçlar için tutarlılık oranının 0,1'den küçük olması beklenir. Fakat CI>0,1 ise tutarsızlık oranı kabul edilebilir seviyenin üzerinde olduğu için karar vericilerin ikili karşılaştırmalardaki kararlarını yeniden gözden geçirmesi gerekmektedir (Saaty ve Vargas, 2000:9).

$$
C R=\frac{C I}{R I}
$$

Adım 6. Kriterlerin öncelik değerleri ile alternatiflerin öncelik değerleri çarpılıp toplanarak birleştirme işlemi yapılır, sonuçlardan en yüksek olanı seçilir.

\subsubsection{Gri İlişkisel Analiz (GİA) Yöntemi}

Gri İlişkisel Analiz, 1982 tarihinde Deng tarafından ortaya çıkarılan, belirsiz ve zayıf bilginin olduğu durumlarda etkili olan bir yöntemdir (Lee ve ark., 2011). Analiz edilen alternatifler arasındaki benzerlikler veya farklılıklar 'gri ilişki' olarak adlandırılır (Kurt, 2008). GST sürecinde Siyah-Gri-Beyaz bilgi kavramı ön plana çıkmaktadır (Liu ve Lin, 2006). "Siyah" bilinmeyen bilgi, "Gri" kısmi bilinen-kısmi bilinmeyen bilgi, "Beyaz" tam bilinen bilgiyi ifade etmektedir. 
E. Noyan - E. Gavcar - C. Tosun Gavcar 11/2 (2019) 835-847

Tablo 10: Siyah-Gri-Beyaz Sistemlerin Karşılaştırılması

\begin{tabular}{|cccc|}
\hline & Siyah & Gri & Beyaz \\
Bilgi Türü & Bilinmiyor & Tamamlanmamış & Biliniyor \\
Görünüş & Koyu & Gri & Parlak \\
Süreç & Yeni & Eski yerine Yeni & eski \\
Özellik & Kaos & Karmaşıklı & Düzen \\
Yöntem & Olumsuz & Geçiş & Olumlu \\
Tutum & Müsamaha içerir & Tolerans & Netlik \\
Çıkarım & Sonuç yok & Çoklu Çözüm & Tek çözüm \\
\hline
\end{tabular}

(Kaynak: Liu ve Lin, 2006.)

GİA' in adımları altı basamaktan oluşmaktadır, bunlar (Lee ve ark., 2011):

- Veri setinin hazırlanması ve karar matrisinin,

- Referans serisinin ve karşılaştırma matrisinin elde edilmesi,

- Karar matrisinin normalize edilmesi,

- Mutlak değer tablosunun oluşturulması,

- Gri ilişki katsayısının hesaplanması,

- Gri ilişki derecelerinin belirlenmesi (Wu, 2006).

Adım 1. Karar matrisinin oluşturulmasında $m^{\prime}$ nin alternatifleri, n'nin ise kriterleri gösterdiği mxn'lik karar matrisinin oluşturulması:

$$
\mathrm{X}=\left(\begin{array}{cccc}
x_{11} & x_{12} & \cdots & x_{1 n} \\
x_{21} & x_{22} & \cdots & x_{2 n} \\
\vdots & \vdots & \ddots & \vdots \\
x_{m 1} & x_{m 2} & \cdots & x_{m n}
\end{array}\right)
$$

Karar matrisinin satırları $(i=1,2, \ldots, m)$ alternatifleri, sütunları $(j=1,2 \ldots, n)$ ise kriterleri gösterir.

Adım 2. Verilerin normalize edilmesinde, karar matrisi veri sıradanlığının sağlanması amacı ile 10, 11 ve 12 numaralı eşitlikler yardımıyla normalize edilir. 10 numaralı eşitlik en büyük değerin katkısı daha çok ise, 11 numaralı eşitlik en küçük değerin katkısı daha iyi ise, 12 numaralı eşitlikte $y j^{*}$ değeri, hedef değere yakın olması için kullanılır.

$$
\begin{aligned}
& x i j=\frac{y i j-\operatorname{Min}\{y i j, i=1,2, \ldots, m\}}{\operatorname{Max}\{y i j, i=1,2, \ldots, m\}-\operatorname{Min}\{y i j, i=1,2, \ldots, m\}} i=1,2, \ldots \ldots, m ; \quad j=1,2, \ldots, n \\
& \quad x i j=\frac{\operatorname{Max}\{y i j, i=1,2, \ldots, m\}-y i j}{\operatorname{Max}\{y i j, i=1,2, \ldots, m\}-\operatorname{Min}\{y i j, i=1,2, \ldots, m\}} i=1,2, \ldots . ., m ; \quad j=1,2, \ldots, n \\
& x i j=\frac{|y i j-y j *|}{\operatorname{Max}\{\operatorname{Max}\{y i j, i=1,2, \ldots, m\}-y i j *, y i j *,-\operatorname{Min}\{y i j, i=1,2, \ldots, m\}}
\end{aligned}
$$

Adım 3. Gri ilişki katsayısının hesaplanmasında, $i$ alternatifinin $j \mathrm{j}$ kriteri için $x i j$ değerine sahip ise herhangi bir alternatifin 1 değerine yakın olması veya 1'e eşit olması için gri ilişki yaratma süreci başlar yani $i$. Alternatif değerinin performansı $j$. kriter için en iyi olduğu durumdur. Referans serisi $x o$ olarak ifade edilir $(x o 1, x o 2, \ldots, x o j, \ldots, x o n)=(1,1, \ldots, 1, \ldots 1)$ ve alternatifin kiyaslanabilir seriye en yakın referans serisine ulaşmayı amaçlamaktadır. Gri ilişki katsayısını hesaplamak demek xij"nin $x o j$ ye yakınlığının bulunmasidir.

Gri ilişki katsayısı, eşitlik 13' te olduğu gibi hesaplanmaktadır.

$$
\mathcal{\gamma}(x o j, x i j)=\frac{\Delta \min +\xi \Delta \max }{\Delta i j+\xi \Delta \max } \quad i=1,2, \ldots m, \quad j=1,2, \ldots, n
$$

$\mathcal{\gamma}(x \circ j, x i j)$, xoj ve xijarasındaki gri ilişki katsayısıdır. 
E. Noyan - E. Gavcar - C. Tosun Gavcar 11/2 (2019) 835-847

$$
\begin{gathered}
\Delta i j=|x o j-x i j|, \\
\Delta \min =\operatorname{Min}\{\Delta i j, i=1,2, \ldots, m ; j=1,2, \ldots, n\}, \\
\Delta \max =\operatorname{Max}\{\Delta i j, i=1,2, \ldots, m ; j=1,2, \ldots, n\},
\end{gathered}
$$

3 değeri, [0,1] değerleri arasında bulunan ve ayırım katsayısı olarak adlandırılan bir katsayıdır. Çalışmalarda genellikle 0,5 olarak kabul edilmektedir.

Adım 4. Gri İlişki Derecelerin Hesaplanmasında 17 numaralı eşitlik kullanılır.

$$
T(x o, x i)=\sum_{i=1}^{n} w j \gamma(x o j-x i j)
$$

Eşitlik 17'deki (xo, xi) , xo ve xi arasındaki gri ilişki derecesidir. wj ifadesi bir katsayıdır ve oran gruplarının kendi içindeki ağırlıkları göstermektedir. Gri ilişki derecesi referans seri ile karşılaştırılan seri arasındaki benzerlik derecesini ifade etmektedir. İlişki derecesinin karşılaştırılması ile bireysel emeklilik şirketlerinin karşılaştırılabilmesine olanak sağlamaktadır.

\subsection{Bulgular}

AHS Yöntemi İle Bireysel Emeklilik Şirketlerinin Değerlendirilmesi

Tablo 11: Karar Matrisi

\begin{tabular}{|cccccc|}
\hline & K1 & K2 & K3 & K4 & K5 \\
\hline A1 & 1,000 & 0,400 & 0,600 & 0,500 & 9,000 \\
A2 & 2,500 & 1,000 & 0,800 & 0,900 & 9,000 \\
A3 & 1,700 & 1,250 & 1,000 & 0,800 & 9,000 \\
A4 & 2,000 & 1,110 & 1,250 & 1,000 & 9,000 \\
A5 & 1,000 & 1,660 & 1,250 & 1,700 & 1,000 \\
\hline
\end{tabular}

Çalışmada beş adet bireysel emeklilik şirketlerinin, katılımcı sayıları, katılımcıların fon tutarları, emekli olan katılımcı ve toplam bireysel emeklilik sözleşmeleri sayıları ve yatırıma yönlenen tutar kriterleri ele alınmıştır. İkili karşılaştırmalar sonucu karar matrisi Tablo 11'de görülmektedir. Tutarlılık oranı 0.01 olarak hesaplanmıştır.

Tablo 12: Normalize Karar Matrisi

\begin{tabular}{|cccccccc|}
\hline & K1 & K2 & K3 & K4 & K5 & Toplam A ğ1rl1k \\
\hline A1 & 0,122 & 0,074 & 0,122 & 0,102 & 0,243 & 0,663 & 0,133 \\
A2 & 0,305 & 0,185 & 0,163 & 0,184 & 0,243 & 1,080 & 0,216 \\
A3 & 0,207 & 0,231 & 0,204 & 0,163 & 0,243 & 1,049 & 0,210 \\
A4 & 0,244 & 0,205 & 0,255 & 0,204 & 0,243 & 1,151 & 0,230 \\
A5 & 0,122 & 0,306 & 0,255 & 0,347 & 0,027 & 1,057 & 0,211 \\
\hline
\end{tabular}

Tutarlılık oranı kontrol edilip karar matrisi normalize edilmiştir. Normalize karar matrisi Tablo 12'de görülmektedir.

\section{Tablo 13: AHP Yöntemi ile Elde Edilen Kriter Ağırlıkları}

\begin{tabular}{|ccc|}
\hline \multicolumn{2}{|c|}{ Kriterler A ğırlıklar Sıralama } \\
\hline K1 & 1,080 & 1 \\
K2 & 0,970 & 4 \\
K3 & 0,926 & 5 \\
K4 & 0,975 & 3 \\
K5 & 1,046 & 2 \\
\hline
\end{tabular}

Tablo 13'teki kriter ağırlıkları sıralaması: K1, K5, K4, K2 ve K3 şeklindedir. Siralama AHP yöntemi ile elde edilen ağırlıklara göre büyükten küçüğe doğru yapılmıştır. Çalışmada, n değeri 5 olup Tablo III' teki rastlantısal indeks değeri ' 1,12 ' olarak kabul edilmiştir. $\lambda$ değer ortalaması $0,01<0,1$ olduğundan sonuç uyum sınırları içindedir. Karşılaştırmadaki tutarsızlık kabul edilebilir sınırlar içindedir. 
E. Noyan - E. Gavcar - C. Tosun Gavcar 11/2 (2019) 835-847

Çalışmada görüşülen 6 adet yatırım yapmayı planlayan birey ve 5 adet bireysel emeklilik danışmanı olan karar vericilere göre en önemli kriter en yüksek kriter ağırlı̆̆ına sahip olan K1 kriteri yani 'katılımcı sayısı' dır. Daha sonra 'yatırıma yönlenen tutar', 'toplam sözleşme sayısı', 'katılımcı fon tutarı' ve 'emekli olan katılımcı sayısı' kriterleri olarak ağırlıklar sıralanmıştır.

Gri İlişkisel Analiz Yöntemi ile Bireysel Emeklilik Şirketlerinin Değerlendirilmesi

Gri ilişkisel analiz yöntemi adımları uygulandığında, Tablo $13^{\prime}$ te gerçek veri setinden oluşan matriste tüm kriterlerin yüksek olması beklendiği için sütunlardaki en büyük değerler referans serisi satırını oluşturmuştur.

Tablo 14: Normalizasyon Matrisinin Oluşturulması

\begin{tabular}{|cccccc|}
\hline & $\begin{array}{c}\text { Maks. } \\
\text { K1 }\end{array}$ & $\begin{array}{c}\text { Maks. } \\
\text { K2 }\end{array}$ & $\begin{array}{c}\text { Maks. } \\
\text { K3 }\end{array}$ & $\begin{array}{c}\text { Maks. } \\
\text { K4 }\end{array}$ & $\begin{array}{c}\text { Maks. } \\
\text { K5 }\end{array}$ \\
\hline A1 & 0,341 & 0,624 & 0,480 & 0,392 & 0,575 \\
A2 & 0,960 & 0,947 & 1,000 & 1,000 & 0,967 \\
A3 & 0,480 & 1,000 & 0,788 & 0,625 & 1,000 \\
A4 & 1,000 & 0,676 & 0,577 & 0,865 & 0,670 \\
A5 & 0,170 & 0,243 & 0,347 & 0,227 & 0,209 \\
\hline
\end{tabular}

Tablo 14 'te veri setine normalizasyon işlemi uygulanmıştır. Normalizasyon, kriterlerin birimden ayrılması işlemidir.

Tablo 15. Gri İlişkisel Katsayı Matrisinin Oluşturulması

\begin{tabular}{|cccccc|}
\hline & K1 & K2 & K3 & K4 & K5 \\
\hline A1 & 0,431 & 0,571 & 0,490 & 0,451 & 0,540 \\
A2 & 0,926 & 0,904 & 1,000 & 1,000 & 0,938 \\
A3 & 0,490 & 1,000 & 0,702 & 0,572 & 0,867 \\
A4 & 1,000 & 0,607 & 0,541 & 0,787 & 0,602 \\
A5 & 0,376 & 0,398 & 0,433 & 0,305 & 0,387 \\
max & 1,000 & & & & \\
min & 0,000 & & & & \\
\& & 0,500 & & & & \\
\hline
\end{tabular}

Tablo 15 'te gri ilişkisel katsayı matrisi oluşturulmuştur. $\Delta$ maks değeri $1.000, \Delta$ min değeri 0,000 ve $\lambda$ değeri literatürde 0,5 olarak kullanılmaktadır.

Tablo 16. Gri İlişkisel Derecelerin Hesaplanması

\begin{tabular}{|cccccccc|}
\hline & K1 & K2 & K3 & K4 & K5 & Ortalama & S1ralama \\
\hline A1 & 0,456 & 0,572 & 0,498 & 0,457 & 0,565 & 0,510 & 4 \\
A2 & 0,879 & 0,871 & 1,000 & 1,000 & 1,000 & 0,950 & 1 \\
A3 & 0,532 & 1,000 & 0,712 & 0,616 & 1,183 & 0,808 & 2 \\
A4 & 1,000 & 0,635 & 0,520 & 0,865 & 0,674 & 0,739 & 3 \\
A5 & 0,336 & 0,333 & 0,333 & 0,305 & 0,333 & 0,328 & 5 \\
\hline
\end{tabular}

Tablo 16' da kriterlerin eşit öneme sahip olduğu durumda gri ilişkisel dereceler hesaplanmış, alternatiflerin sıralamaları yapılmıştır. Buna göre bireysel emeklilik şirketleri alternatiflerini sıralaması A2, A3, A4, A1 ve A5 şeklindedir. 
E. Noyan - E. Gavcar - C. Tosun Gavcar 11/2 (2019) 835-847

Tablo 17: Kriterlerin Ağırlıklandırılması Durumunda Gri İlişkisel Dereceler ve Alternatiflerin Siralanması

\begin{tabular}{|cccccccc|}
\hline & K1 & K2 & K3 & K4 & K5 & Г0i & Siralama \\
A ğırlıklar & & & & & & & \\
& $\mathbf{1 0 , 8 0 \%}$ & $\mathbf{9 , 7 1 \%}$ & $\mathbf{9 , 2 6 \%}$ & $\mathbf{9 , 7 5 \%}$ & $\mathbf{1 0 , 4 6 \%}$ & & \\
\hline A1 & 0,456 & 0,572 & 0,498 & 0,457 & 0,565 & 0,255 & 5 \\
A2 & 0,879 & 0,871 & 1,000 & 1,000 & 1,000 & 0,474 & 1 \\
A3 & 0,532 & 1,000 & 0,712 & 0,616 & 1,183 & 0,404 & 2 \\
A4 & 1,000 & 0,635 & 0,520 & 0,865 & 0,674 & 0,373 & 3 \\
A5 & 0,336 & 0,333 & 0,333 & 0,305 & 1,333 & 0,269 & 4 \\
\hline
\end{tabular}

Tablo 17'de kriterlerin ağırlıklandırılması durumunda ortalamalar ve sıralamalar görülmektedir. Bireysel emeklilik şirketlerinin ortalama değerleri büyükten küçüğe doğru sıralandığında sıralama: A2, A3, A4, A1, A5 ve A1 şeklindedir.

AHS ve GİA yöntemlerinin uygulanması sonucu sıralamalar aşağıdaki gibidir:

AHS yöntemi uygulanması sonucuna göre kriterlerin siralanmas1: K1-K5-K4-K2-K3,

GİA yöntemi uygulanması sonucuna göre alternatiflerin sıralanması: A2-A3-A4-A1-A5,

GİA yöntemi uygulanması sonucuna göre kriterlerin ağırlıklandırılması durumunda ise alternatiflerin sıralanması: A2-A3-A4-A5-A1 şeklindedir. GİA yönteminde, AHS yönteminden elde edilen ağırlıklar kullanıldığında nihai sıralamada sadece A1 ve A5 kodlu bireysel emeklilik şirketlerinin yerleri değişmiştir. Diğer bireysel emeklilik şirketlerinin sıralaması, ağırlıklandırma işlemi sonrasında da aynı kalmıştır.

\section{Tartışma ve Sonuç}

Hem finansal piyasalara hem de ekonomiye büyük katkısı olan BES' in, Türkiye'de 16 yıllık geçmişi ile yatırım fonlarının uzun vadede kaynak sağlaması açısından katkısı büyüktür ancak toplanan kaynak, devlet katkısına rağmen toplam Gayri Safi Yurt içi Hasıla' nın \% 4'ü ile sınırlı kalmıştır. Bu oran OECD ülkelerinde \% 51'dir. Bu oranın Türkiye'de düşük olmasının başlıca sebepleri, enflasyon oranının yüksek olması, ortalama gelirin ise düşük olmasıdır.

Yatırım yapacak olan bireylerin bireysel emeklilik şirketini belirlerken dikkate aldıkları kriterler farklılık gösterebilmektedir. Bireylerin yatırım yapmaları yönünde teşvik edilmesi, bilinçlendirilmesi, yatırımların doğru şekilde yönlendirilmesi, bu yönde çalışmaların yapılması, bireysel emeklilik sistemi ile ilgili olumsuz düşüncelerin değiştirilmesi, bireysel emeklilik şirketlerinin, reklam faaliyetlerinin artırılması ve devletin katkı payı tutarını artırılması gibi öneriler verilebilir.

Çalışmada, yatırım yapacak olan bireylere yardımcı olabilmek için bireysel emeklilik şirketi sıralama problemi ÇKKV yöntemlerinden AHP ve GİA yöntemlerinin birleşimine dayanan bir yaklaşım ile ele alınmıştır. AHP yöntemi beş adet bireysel emeklilik şirketlerinin kriter ağırlıkları; katılımcı sayıları $(1,080)$, katılımcıların fon tutarları $(0,97)$, emekli olan katılımcı $(0,926)$, toplam bireysel emeklilik sözleşmeleri sayıları $(0,975)$ ve yatırıma yönlenen tutar $(1,046)$ olarak hesaplanmıştır. AHP yöntemi, kriter ağırlıklarını belirlemede çalışmalarda sıklıkla kullanılmaktadır.

Çalışmada 6 adet yatırım yapmayı planlayan birey ve 5 adet bireysel emeklilik danışmanı ile yüz yüze görüşülüp AHS yöntemindeki ikili karşılaştırmalar bu görüşmelere istinaden hesaplanmıştır. AHS yöntemine göre en önemli kriterin 'katılımcı sayısı' olduğu sonucuna varılmıştır. Bu durumda katılımcıların birbirlerini etkiledikleri, yatırım yapmayı planlan bireylerin birbirlerinin tavsiyelerini aldıkları, daha önce yatırım yapmış bireylerin, aldıkları hizmetlerden memnun kaldıkları söylenebilir. 'Emekli olan katılımcı sayısı' kriter ağırlığı sıralamada en son sırada yer almıştır.

GİA yöntemi uygulaması ise AHS yönteminden elde edilen ağırlıklara göre yapılmıştır. Örneklemi sınırlı olan çalışmalarda GİA yöntemi yaygın olarak kullanılmaktadır.

Çalışmadan elde edilen bulgular Genç ve ark. (2015), Dinçer ve Görener (2011) ve Ertuğrul \& Öztaş (2016)'ın yapmış oldukları çalışmalar ile benzerlik göstermektedir. Karar vericiler değiştikçe kriter ağırlıkları da değişeceğinden uygulama sonuçları farklılaşacaktır.

Gelecekte yapılacak olan çalışmalarda karma yöntemler kullanılabilir, farklı alanlara uygulanacak çalışmalar çeşitlendirilebilir. Kriterlerin ağırlıkları diğer ÇKKV yöntemleri ile de elde edilebilir. 


\section{E. Noyan - E. Gavcar - C. Tosun Gavcar 11/2 (2019) 835-847}

\section{Kaynakça}

Altay, M. (2013). Türkiye'de bireysel emeklilik sistemi: Aydın örneği. Yüksek Lisans Tezi. Adnan Menderes Üniversitesi Sosyal Bilimler Enstitüsü Maliye Anabilim Dalı.

Apak, S. ve Taşciyan, K. H. (2010). Türkiye'de bireysel emeklilik sisteminin gelişimi, Ekonomi Bilimleri Dergisi, 2, (2), 121-129.

Ayaydın, H. (2013). Türkiye'deki emeklilik yatırım fonlarının performanslarının analizi, Çanakkale Üniversitesi Sosyal Bilimler Enstitüsü Dergisi, 22(2), 59-80.

Aydın, Ö. Öznehir, S. ve Akcalı, E. (2009). Ankara için optimal hastane yeri seçiminin Analitik Hiyerarşi Süreci ile modellenmesi, Süleyman Demirel Üniversitesi İktisadi ve İdari Bilimler Fakültesi Dergisi, 14 (2), 69- 86.

Boulier, J. F., Shao J. H. and Grégory T. (2001). Optimal management under stochastic interest rates: the case of a protected defined contribution pension fund, Insurance: Mathemetics and Economics, 28( 2), 173-189.

Can, Y. (2010). Bireysel emekliliğin Türkiye'deki durumu ve gelişimi. Ekonomi Bilimleri Dergisi, 2( 2), 139146.

Çelikbilek, Y. (2018). Çok kriterli karar verme yöntemleri açıklamalı ve karşılaştırmalı sağlık bilimleri uygulamaları ile, Nobel, Ankara.

Dağlı, H., Bank, S. ve Er, S. (2008). Türkiye'deki bireysel emeklilik yatırım fonlarının performans değerlendirmesi, 40, 84-95.

Dinçer, H ve Görener A. (2011). Performans değerlendirmesinde AHP - VIKOR VE AHP - TOPSIS yaklaşımları: hizmet sektöründe bir uygulama, Mühendislik ve Fen Bilimleri Dergisi, 29, 244-260.

Ege, İ, Topaloğlu, E. ve Coşkun, D. (2011). Türkiye'deki emeklilik yatırım fonlarının yatırım performanslarının analizi, Ekonomi Bilimleri Dergisi, 3(1), 79-89.

Ertuğrul, İ. ve Öztaş, T. (2016). Bireysel emeklilik planı seçiminde karar verme yöntemlerinin uygulanması: COPRAS ve TOPSIS örneği, ÇKÜ Sosyal Bilimler Enstitüsü Dergisi, 7 (2), 165-186.

Emeklilik Gözetim Merkezi (EGM), http://www.egm.org.tr, (Erişim tarihi: 22 Şubat 2019).

https://www.egm.org.tr/bilgi-merkezi/istatistikler/bes-istatistikleri/katilimci-yas-dagilimi/, (Erişim tarihi: 22 Şubat 2019).

https://www.egm.org.tr/bilgi-merkezi/istatistikler/bes-istatistikleri/en-fazla-katilimcinin-yerlesik-oldugu-ilk10-il//, (Erişim tarihi: 22 Şubat 2019).

https://www.egm.org.tr/bilgi-merkezi/istatistikler/bes-istatistikleri/katilimci-sayisi/(Erişim tarihi: 22 Şubat 2019).

http://web2.egm.org.tr/webegm2/chart/besgosterge/wg_sirketview_tablolu.asp?raportip=10, (Erişim tarihi: 25 Şubat 2019).

http://www.tkyd.org.tr/assets/raporlar/EYF_Performans_2018_Aralik pa85f5af46e7a0be5591aefad0dc3890. pdf (Erişim tarihi: 25 Mayıs 2019).

Genç, T., Kabak, M., Köse E. ve Yılmaz Z. (2015). Bireysel emeklilik sistemi seçimi problemine ilişkin MACBETH yaklaşımı.

https://www.finansdanismanim.com/2018-yili-en-iyi-50-bes-fonu-getiri-siralamasi-ve karsılaştırmasi// (Erişim tarihi: 25 Şubat 2019).

Göktolga Z., G. ve Karakış, E. (2018). Bireysel emeklilik şirketlerinin finansal performanslarının bulanık AHP ve VIKOR Yöntemleri ile analizi, Cumhuriyet Üniversitesi, İktisadi ve İdari Bilimler Dergisi, 19, 1.

İşcan, C.C, Aydın, A.E. (2018). Zaman Tercihi, Hazzın Ertelenmesi ve Bireysel Emeklilik Kararları, İşletme Araştırmaları Dergisi, 10 (4), 443-458. 
E. Noyan - E. Gavcar - C. Tosun Gavcar 11/2 (2019) 835-847

Karakaya, A., Kurtaran, A. ve Dağlı, H., (2014). Bireysel Emeklilik Şirketlerinin Veri Zarflama Analizi ile etkinlik ölçümü: Türkiye örneği, Yönetim ve Ekonomi Araştırmaları Dergisi. 22, 1-23.

Korkmaz, T. ve Uygurtürk, H. (2007). Türk emeklilik fonlarının performans ölçümünde Regresyon Analizi'nin kullanılması, ZKÜ Sosyal Bilimler Dergisi, 3(5), 37-52.

Kula, V., Kandemir, T. ve Baykut E. (2016). Borsa İstanbul'da işlem gören sigorta ve BES şirketlerinin finansal performansının gri ilişkisel analiz yöntemi ile incelenmesi, Afyon Kocatepe Üniversitesi İktisadi ve İdari Bilimler Fakültesi Dergisi, 18(1), 37-53.

Kurt, G. (2008). Gri ilişki çözümlemesi kullanılarak üniversiteli öğrencilerinin çeşitli kaygılarının değerlendirilmesi, Akademik Bakış, Uluslar arası Hakemli Sosyal Bilimler e-dergisi, 14: 1-10.

Lee, W., S. and Lin, Y., C. (2011). Evaluating and ranking energy performance of office buildings using grey relational analysis. Energy Policy, (36), 2551-2556.

Liu, S. and Lin, Y. (2006). Grey information. Springer: 503, Almanya.

Emeklilik Yatırım Fonları Performans Raporu Aralık 2018

OECD Global Pension Statistics, https://www.oecd.org/daf/fin/private-pensions/Pension-Funds-in-Figures2018.pdf (Erişim tarihi: 25 Şubat 2019).

Peker, İ. ve Baki, B. (2011). Gri İlişkisel Analiz Yöntemi ile Türk sigortacıllk sektöründe performans ölçümü, Uluslararası Ekonomi ve İdari Araştırmalar Dergisi, 4 (7), 1-18.

Saaty, T .L. and Vargas, L.G. (2000). models, methods, concepts and applications of the Analytic Hierarchy Process, Boston: Kluwer Academic Publishers.

Saaty 2008. Decision making with the Analytic Hierarchy Process, Int.J. Services, 1(1), 83-98.

Sezgin, S. ve Yıldırım, T. (2015). Türkiye'de bireysel emeklilik sisteminin etkinliği. Eskişehir Osmangazi Üniversitesi İktisadi ve İdari Bilimler Fakültesi Dergisi, 10 (2), 123- 140.

Sönmez, H. (2012). Determination of the criteria preferred in entering private pension system by analytical hierarchy process, Anadolu Üniversitesi Sosyal Bilimler Dergisi, 12(3), 83-92.

Şener, O. ve Akın, F. (2010). Özel emeklilik fonları ve Türkiye'de bireylerin bireysel emeklilik sistemine giriş kararlarını etkileyen faktörlerin belirlenmesi üzerine bir araştırma, Marmara University Journal of the Faculty of Economic \& Administrative Sciences, 29(2), 291-321.

Tzeng, G. H. and Huang, (2011). Multi attribute decision making: methods and applications, crs pres: USA.

Vaidya and Kumar, (2006). Analytic hierarch process: an overview of applications, European Journal of Operational Research, 169, 1-29.

Wu, H.Y., Tzeng, G.H. and Chen, Y.H. (2009). A Fuzzy MCDM approach for evaluating banking performance based on balanced score card, Expert Systems with Applications, 36 (6), 10135-10147. 